\title{
EXPERIMENTAL INVESTIGATION OF FRICTION WELDING ON SIMILAR AL PLATE AND TUBE
}

\author{
DR. K.BALAJI ${ }^{1}$, DR. R. LALITHA NARAYANA ${ }^{2}$, V. JOHN BUNYAN ${ }^{3} \&$ N. BULLI RAJU ${ }^{4}$ \\ ${ }^{I}$ Professor, Department of Mechanical Engineering, V.S.M. College of Engineering, Ramachandrapuram, E.G. Dt., A.P., India \\ ${ }^{2}$ Professor, Department of Mechanical Engineering., Swarandhra College of Engineering, Narsapur, W.G. Dt., A.P., India \\ ${ }^{3,4}$ Assistant Professor, Department of Mechanical Engineering, Swarandhra College of Engineering, Narsapur, W.G. Dt., A.P., \\ India
}

\begin{abstract}
The similar metal joint of 'Al' plate to 'Al' tube is essential in all most all industries now a days because of less weight, no inter metallic formation, environmental friendliness. For this work, friction welding process using an external tool was attempted to join 'Al' plate to 'Al' tube. Friction welding finds increasingly widespread industrial application as manufacturing method for joining parts in Fabrication, Automobile industries. Friction welding method as a mass production process is finding increasing industrial acceptance, for joining similar materials. For this present study, an experimental set up was designed and friction welding of 'Al' plate to 'Al' tube. Metals are taken in commercially pure form so as to understand the basic mechanism of joining. Firstly seeing the macrostructure for the samples having different hole diameters on the tube. Secondly finding the tensile strength. Later, finding the vicker's hardness test for the samples by comparing with tube, base metal and interface. Finally the results obtained were shown and discussed.
\end{abstract}

KEYWORDS: Friction Welding, Similar Metals, Tensile Strength, Vicker's Hardness

Received: Jun 08, 2020; Accepted: Jun 28, 2020; Published: Aug 29, 2020; Paper Id.: IJMPERDJUN2020958

\section{INTRODUCTION}

Friction welding is a method of manufacturing which is being used extensively in all areas due to its more advantages such as low heat input, less production time, easy of manufacture, easy of machining, light in weight and environmental friendliness. Friction welding is one of the most important welding methods, which is more important than other methods. This process produces heat by converting mechanical energy into thermal energy at the interfaces of components during rotation under pressure. The most important parameters of friction welding are friction time friction pressure turbulence stress turbulence and rotational speed must control these factors so as to obtain a uniform and strong joint. These factors must be controlled so as to obtain a uniform and strong joint. For our Al plate to $\mathrm{Al}$ tube having good joint strength can also be joined successfully by using this method. In practice, friction welding is divided into continuous drive friction welding and inertia friction. Welding. In the submitted study, since continuous drive is considered, the principles of continuous drive are described below. In the continuous drive friction welding method one part is rotated and the other is rotated at a constant speed $\mathrm{n}$ the two parts are held together under axial pressure $\mathrm{p} 1$ for a certain friction time $\mathrm{t} 1$. The clutch is then detached from the drive and the rotary component stops within braking time $\mathrm{t} 2$, whereas the axial pressure at the fixed part increases to a higher forging pressure $\mathrm{p} 2$ for the predetermined turbulence time $\mathrm{t} 4$ parameters. In the inertia welding method, the second part is held stationary for welded, while the other part is clamped in a spindle chuck, usually with attached 
the fly wheels. The fly wheel and chuck assembly is rotated to a certain speed $(n)$ to store a predetermined amount of energy.

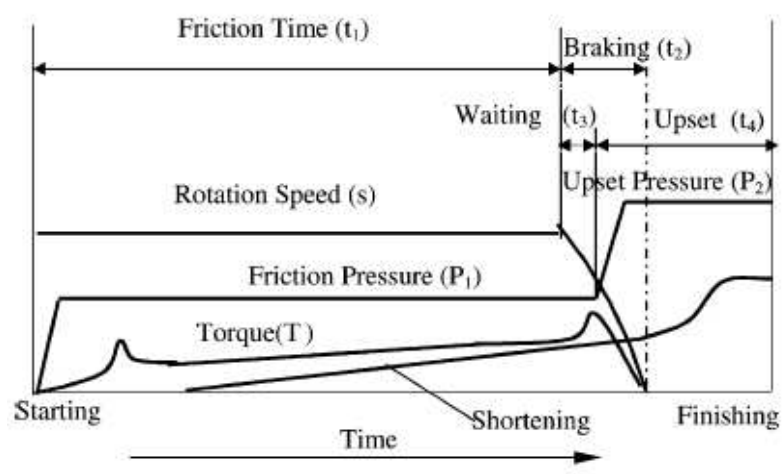

Fig. 1. Parameters on continuous drive friction welding.

Then, the flywheel is declutched, and the two parts are brought together under axial pressure $(P 1)$ for welding. Friction between the parts decelerates the flywheel converting stored energy to frictional heat.

Considerable research studies were carried out to explore the friction welding process by various researchers. Vill and Tylecote investigated the friction welding in general. Jenning investigated the properties of the dissimilar materials welded by friction welding. Lucas investigated process parameters on friction welding. Kinley investigated the inertia friction welding. Fomichev investigated the friction welding of high-speed tool steels to structural steels [1-6]. Later, the effects on the plastically deformed steel of the friction welding examined relation between "friction time-workpiece diameter", "loss of length-forging pressure" and "carbon equivalent-hardness variation". The effects of the parameters that were rotation speed, friction pressure and forging pressure in all friction-welding methods for steel. investigated the mechanical and the metallurgical properties of dissimilar materials welded by friction welding.

In light of previous studies this paper deals with an investigation on the effect of interaction time in friction welding on the macro-structure, tensile strength and vicker's hardness of similar metal combination. Al plate to Al tube combinations are in use almost all industries. Hence, this study assumes technological importance.

\section{EXPERIMENTAL PROCEDURE}

The setup used in the friction welding experiments is shown in the fig. 2

\section{Geometry of Specimens and Testing Materials in Friction Welding Experiments}

The chemical compositions of material used in the experiments are given in table 1.Sample dimensions are shown in figure 3.

Table 1

\begin{tabular}{|c|c|c|c|c|c|c|c|}
\hline $\begin{array}{c}\text { Chemical } \\
\text { Composition }\end{array}$ & Al & Si & Fe & Cu & Mg & Ni & Mn,Zn, \\
\hline Wt\% & 83.39 & 10.9 & 0.52 & 1.31 & 1.05 & 2.32 & 0.494 \\
\hline
\end{tabular}




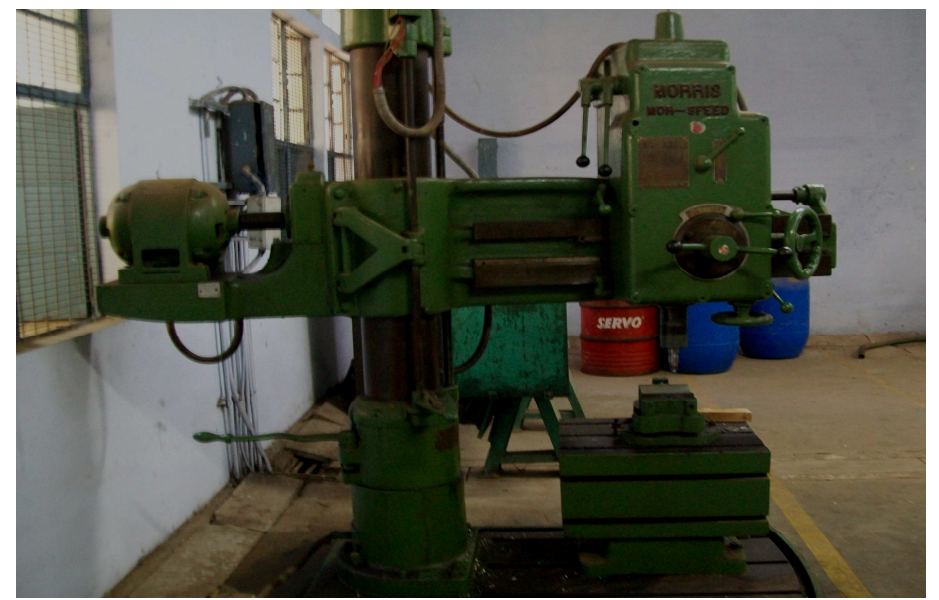

Figure 2: Universal Radial Drilling Machine.

\section{Selection of Welding Parameters and Experimental Approach}

The welding parameters that are used in present friction welding process is shown in the table 2 .

\section{Welding Parameters}

Table 2

\begin{tabular}{|c|c|c|c|}
\hline S. No & Welding Speed(rpm) & Clearance between Tool Pin \& Tube(mm) & Shoulder Diameter(mm) \\
\hline 1 & 1030 & 1 & 30 \\
\hline
\end{tabular}

We can achieve best results with these welding parameters.

\section{Experimental Approach}

In this firstly preparing five samples of tubes by making different types of holes on it, like

- Small hole of $2 \mathrm{~mm}$ size

- Big hole of $3 \mathrm{~mm}$ size

- Rectangular vertical hole

- Rectangular horizontal hole

- Rectangular top to bottom hole

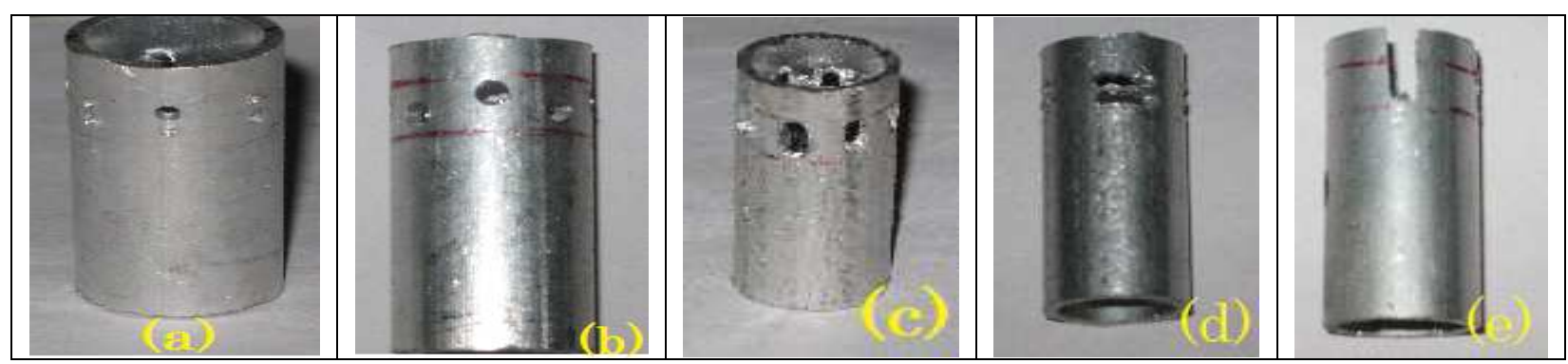

Figure 3: Different Holes on Al Tube.

After that insert all the five tubes into five Al plates of same diameter hole and do the friction welding process with the help of radial drilling machine. The welded joints were subjected to macrostructure analysis, tensile strength test and vicker's hardness test. The macro structure analysis was done by etching with Tukker's etchant and identify the 
structures with the help of image analyzer, the joint strength was determined using tensometer and hardness was found by vicker's hardness test machine.

From the all above we have studied and prove that the small hole tube sample only having the high tensile strength, high hardness and no interface in the welded zone.

\section{RESULTS AND DISCUSSIONS}

\section{Macrostructure}

Fig.5 shows the macro structure of welded samples. For finding the macro structure we have used tukker's etchant. The combination of tukker's etchant is

\section{$4.5 \mathrm{ml} \rightarrow \mathrm{HNO}_{3}, 2.5 \mathrm{ml} \rightarrow \mathrm{H}_{2} \mathrm{O}, 1.5 \mathrm{ml} \rightarrow \mathrm{HCl}, 1.5 \mathrm{ml} \rightarrow \mathrm{HF}$}

In general it is observed that the tube which is having small hole in the similar metal combination experienced more interlocking with each other. So that only there is no any presence of interface at the welded joint. As the hole size on the tube increasing in the similar metal combination we can observe the interface line.

\section{Tensile Strength}

The tensile strength machine.Table.3 shows the tensile strength (MPa) values for five different diameter holes sizes.

Table 3: Tensile Strength

\begin{tabular}{|c|l|c|}
\hline S. No & \multicolumn{1}{|c|}{ Tube Condition } & Tensil Strenth (M.PA) \\
\hline 1 & Small hole & 62.19 \\
\hline 2 & Big hole & 53.90 \\
\hline 3 & Rectangle vertical hole & 43.95 \\
\hline 4 & Rectangle horizontal hole & 41.46 \\
\hline 5 & Rectangle vertical top to bottom & 39.80 \\
\hline
\end{tabular}

The effects of tube conditions on welding strength of the joints were examined in the friction welding process.

The results of the set of welding experiments is shown in the table.3.

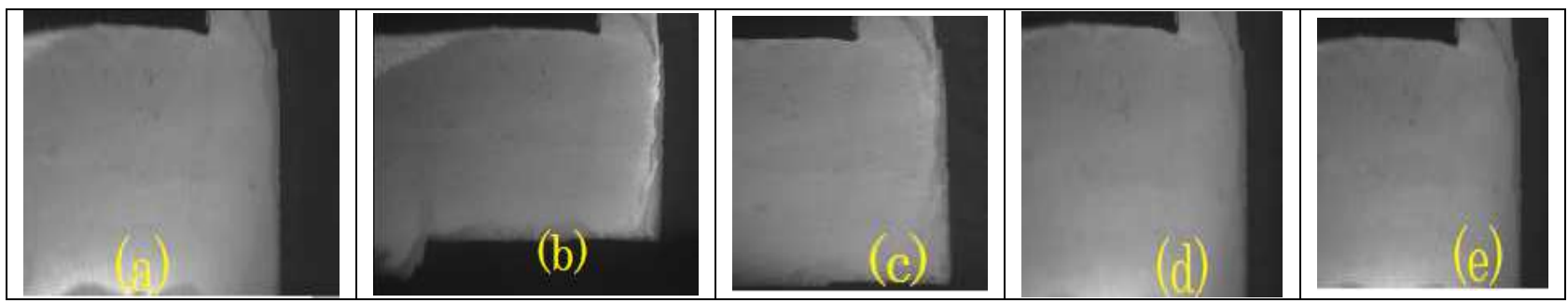

Figure 4: Small Hole.

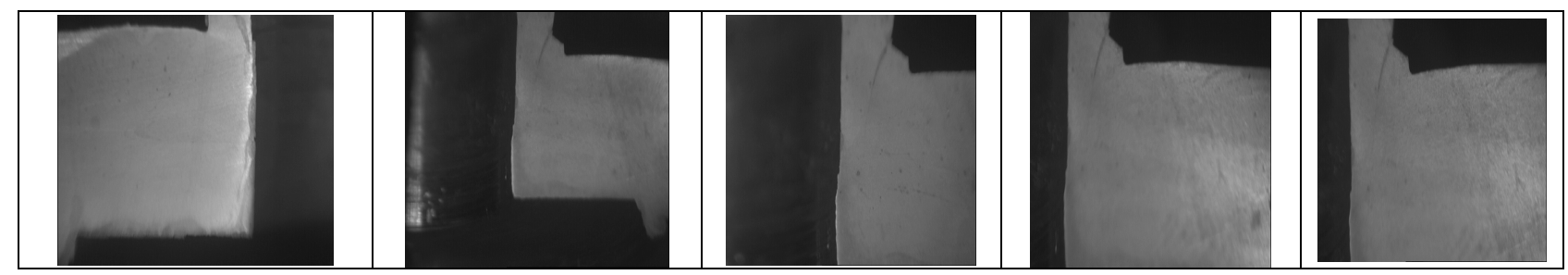

Figure 5: Big Hole. 


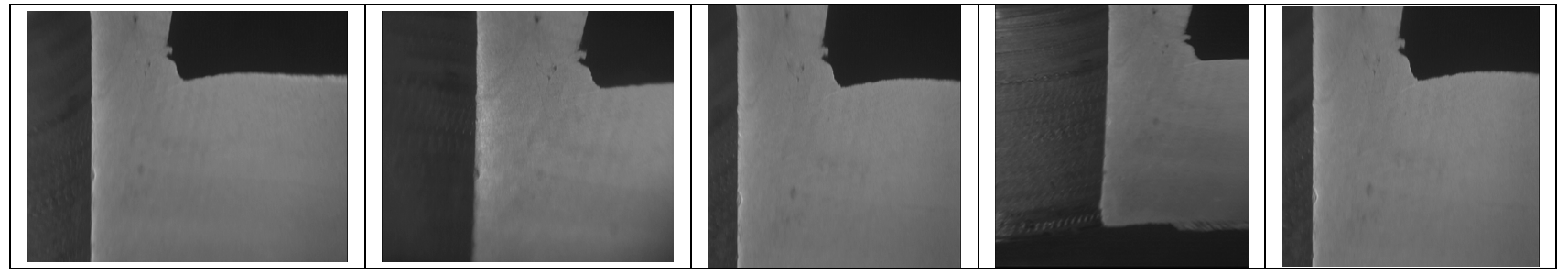

Figure 6: Rectangle Vertical Holes.
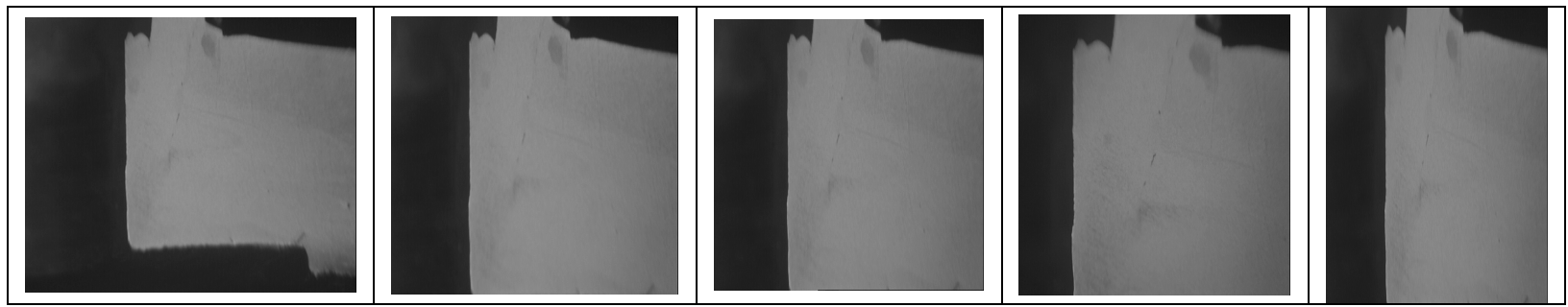

Figure 7: Rectangle Horizontal Holes.
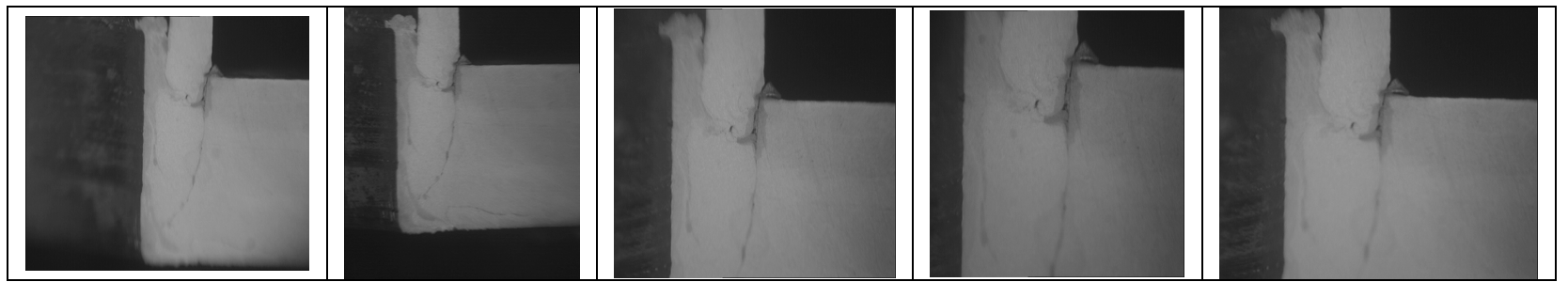

Figure 8: Rectangle Top to Bottom.

The welding strength of the joints reaches max. when the hole diameter is less on the tube. As the area on the tube increases the welding strength of the joint reaches minimum. In general it is observed that in similar metal combination as the diameter of hole size is increasing the strength will decreases. Similarly in case of Al plate to Al tube joint as the hole size is increasing in the tube the strength also decreases. Here small holes will give max. Tensile strength. Here we have proved 62.19 MPa tensile strength for small hole and 39.80MPa tensile strength for rectangular top to bottom. The graph is drawn between Tensile strength Vs tube condition is shown in fig.7.

\section{Hardness Variations}

Hardness variation was obtained by vicker's hardness test. Hardness variations on vertical direction and tube conditions on horizontal directions are shown in the fig.8.the hardness test values on tube, base metal and interface are shown in the table 4

Table 4

\begin{tabular}{|c|l|c|c|c|}
\hline S. NO & TUBE CONDITION & TUBE (Hv) & BASE METAL (Hv) & INTERFACE (Hv) \\
\hline 1 & Small hole & 50.60 & 50.70 & 73.22 \\
\hline 2 & Big hole & 51.03 & 50.875 & 72.18 \\
\hline 3 & Rectangle vertical hole & 50.45 & 50.46 & 71.96 \\
\hline 4 & $\begin{array}{l}\text { Rectangle horizontal } \\
\text { hole }\end{array}$ & 51.53 & 51.0 & 72.10 \\
\hline 5 & $\begin{array}{l}\text { Rectangle vertical top to } \\
\text { bottom }\end{array}$ & 50.54 & 51.1 & 78 \\
\hline
\end{tabular}

It is clearly understood that as the holes on the tube increases continuously the hardness values are also decreasing. 


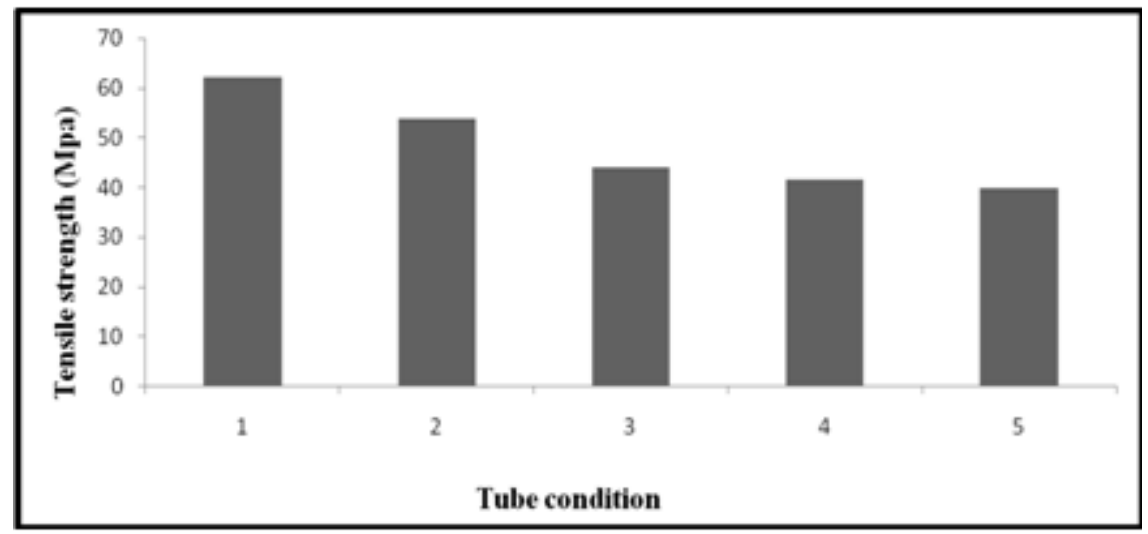

Figure 9

\section{CONCLUSIONS}

The influence of the hole size in the tube on macro-structure, tensile strength, vickers hardness of the friction welding on five similar metal samples namely small hole, big hole, rectangular vertical hole, rectangular horizental hole, rectangular top to bottom hole has been investigated.

- The small hole tube sample only having the high tensile strength, high hardness and no interface in the welded zone.

- 62.19 MPa tensile strength for small hole and 39.80MPa tensile strength for rectangular top to bottom.

- The Hardness of small hole is high and rectangle vertical hole is less.

\section{ACKNOWLEDGEMENT}

I am very much thankful to my Academic Director Sri M.S.N. Murthy, VSM Group of Institutions Ramachandrapuram for his Support \& Encouragement to this Work.

\section{REFERENCES}

1. Mümin ,Sahin, H. Erol Akata, Joining with friction welding of plastically deformed steel, Journal of Materials Processing Technology 142 (2003) 239-246

2. Prathyusha, B. G. R., Naveen Janjanam, and KV Narasimha Rao \& G. Sandeep. "Numerical Investigation on Shell \& Tube Heat Exchanger with Segmental and Helix Baffles." International Journal of Mechanical and Production Engineering Research and Development, 8 (3) (2018): 183-192.

3. Müumin Sahin, Joining with friction welding of high-speed steel and medium-carbon steel, Journal of Materials Processing Technology 168 (2005) 202-210.

4. Kalbande, S. R., Sneha Deshmukh, and V. P. Khambalkar. "Evaluation study of solar water desalination system for saline track area of Vidharba region." Int. J. Appl. Nat. Sci.(IJANS) 6.1 (2017): 55-64.

5. Mumin Sahin a,, H. Erol Akata a, Turgut Gulmez, b, Characterization of mechanical properties in AISI 1040 parts welded by friction welding, Materials Characterization 58 (2007) 1033-1038.

6. K. Balaji, K. Brahma Raju, \& K. Venkata Subbaiah, "Effect of Temperature on Corrosion Behavior of Dissimilar weldments of Inconel 718 Vs ASS 316 with mixer of sodium sulfate and vanadium pentoxide Deposit”. International journal of Engineering and Technology, (UAE) 7 (4) (2018) 4862-4865, 
7. S.D. Meshram, T. Mohandas, G. Madhusudhan Reddy, Friction welding of dissimilar pure metals, Journal of Materials Processing Technology 184 (2007) 330-337.

8. Ismail, Mahmud Rasheed, Muhannad Al-Waily, and Ameer A. Kadhim. "Biomechanical Analysis and Gait Assessment for Normal and Braced Legs." International Journal of Mechanical \& Mechatronics Engineering IJMME-IJENS 18.03 (2018).

9. H.C. Dey, M. Ashfaq, A.K. Bhaduri, K. Prasad Rao, Joining of Titanium to 304L Stainless Steel by Friction Welding, Journal of Materials Processing Technology S0924-0136(09)00241-

10. M. Vangalapati, K. Balaji and A. Gopichand "Optimization of Process Parameters in Surface Finishing of Al 6061 by using Magnetic Abrasive Finishing Process” Materials Today proceedings 18(2019) 3357-3364. Scopus indexed journal

11. Balakrishnan, V. I. D. Y. A., K. P. Asifa, and K. C. Chitra. "Genotoxic potential of nonylphenol in freshwater fish, Oreochromis mossambicus." International Journal of Applied and Natural Sciences 3.2 (2014): 81-88.

12. 8. K. Venkata Subbaiah, K. Balaji, K. Brahma Raju, \& "High Temperature Oxidation and Corrosion studies on Dissimilar Weldments in Aggressive solution of a $\mathrm{Na}_{2} \mathrm{So}_{4}-\mathrm{V}_{2} \mathrm{O}_{5}$ environment" International Research Journal of Engineering and Technology (IRJET) Volume 6, Issue 1, January 2019. 

